Journal of Computer Science 7 (6): 823-831, 2011

ISSN 1549-3636

(C) 2011 Science Publications

\title{
A Simple Algorithm to Assess the Speed Stability of Induction Generators
}

\author{
Alexandre de Assis Mota and Lia Toledo Moreira Mota \\ Exact, Environmental and Technological Sciences Center, \\ Pontifical Catholic University of Campinas, \\ Rodovia D. Pedro I, km 136, Parque das Universidades, \\ Campinas-SP, CEP 13086-900, Brazil
}

\begin{abstract}
Problem statement: The speed stability if Induction Generators (IG) can be defined as its ability to remain connected to the electric network, operating at a mechanical speed close to the speed associated to the actual system frequency, after being subjected to a perturbation. This IG behavior is normally studied using dynamical methods that are determined through time-consuming simulations and are difficult to implement in simpler computational devices, such as microcontrollers, that are the basic component of electronic protection relays. In this way, the possibility to assess the speed stability of IGs through a simpler method becomes very desirable. Approach: This paper proposes a simple analytical method for assessing the speed stability of induction generators connected to distribution systems that can be easily implemented in microcontrollers, based on the determination of its critical speed and critical time. The formulation of the proposed method is founded on the electricalmechanical equilibrium equations associated to the steady-state operation condition in the classical induction machine model. Results: The developed method has four simple steps, based on mathematical equations obtained from the classical IG model and presented a mean difference less than $5 \%$ when compared with results obtained by dynamical simulations, tested in the context of a distribution electrical network that considers generator parameters, line parameters and capacitor bank variation. Conclusions/Recommendations: This analytical approach can be used as a guide to significantly reduce the simulation efforts, required to assess the induction generators stability in distribution networks and permits its implementation in less complex computational contexts, like microcontrollers. The reliability of the method has been attested by extensive simulation results.
\end{abstract}

Key words: Simple algorithm, speed stability, induction generators, distributed generation, analytical formulation, simulation results, proposed method, computational contexts, speed associated, rotor current, possible equilibrium, stability assessment

\section{INTRODUCTION}

Nowadays, the penetration of distributed generation in electric power networks is encouraged by different causes, including changes in the regulatory scenario, minimization of environmental impacts, economical issues and the need for more flexible electric networks (Willis and Scott, 2000; Mota and Mota, 2009). In this context, a crescent number of Induction Generators (IGs) have been connected to distribution systems, commonly through small generation plants using hydro, thermal, solar or wind energy sources (Jenkins et al., 2000; Akhmatov et al., 2003; Parsons, 1984; Barbi, 2008; Lubis et al., 2009; Santos et al. 2010). The analysis of the impacts of the installation of these induction generators in the distribution network and also of their operational characteristics under normal and fault conditions, becomes crucial for the network operation, as described in (Akhmatov, 2003). In this context, an important phenomenon related to the IG operation that deserves special attention is its speed stability. According to Samuelsson and Lindahl (2005), the speed stability can be defined as the ability of an IG to remain connected to the electric network, operating at a mechanical speed close to the speed associated to the actual system frequency, after being subjected to a perturbation.

This IG behavior is normally studied using dynamical simulation methods. These methods are easy to apply and offer flexible models and usually a large number of simulations, that can be extremely timeconsuming, must be performed in order to achieve

Corresponding Author: Alexandre de Assis Mota, 1-Exact, Environmental and Technological Sciences Center, Pontifical Catholic University of Campinas-Rodovia 
satisfactory results. Although simulations may not be a significant problem in electric power systems analysis, they do not provide insight in the physical relations among electrical parameters of the network components, since the models are encapsulated in the software and the user is blind to their interaction. In other hand, the simplicity of the algorithm permits its implementation in less complex computational contexts, like microcontrollers, where the usage of simulation methods is unfeasible.

\section{MATERIALS AND METHODS}

General outline of the approach: The central idea of this work is to develop an analytical method for assessing the speed stability of IGs connected to distribution systems, yet still yielding accurate results. Figure 1 illustrates the equivalent circuit that represents the connection of an IG to a generic distribution network. In this figure, the bus "IB" corresponds to the infinite bus-a bus with a constant voltage level that does not depend on the network configuration and operation condition-that, considering the generator's connection to distribution level, can satisfactorily represent the electric power network.

The analysis of the IG speed stability is based on the critical speed concept, firstly described in (Akhmatov, 2003). The critical speed can be defined as the maximum speed associated to the shaft that will not imply in an unstable behavior of the generator. Consequently, this is the fundamental parameter that determines the stability of induction machines during fault conditions. So, the methodology adopted to estimate this speed and to assess the IG stability is summarized as follows:

- Determination of a generic equivalent model for the IG and its electrical interconnection (shown in Fig. 1)

- Determination of the rotor current I.

- Determination of equilibrium equations under steady-state conditions, involving electrical and mechanical torques

- Definition of fault conditions

- Determination of the critical speed

- Development of the analytical method for assessing the stability of an induction generator under fault conditions (determination of the critical time

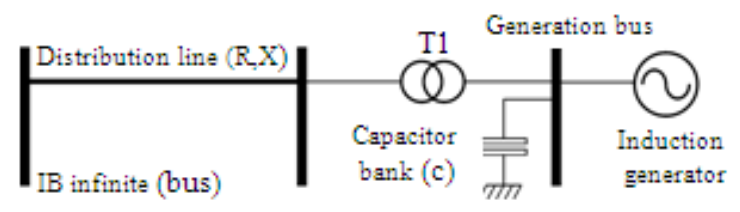

Fig. 1: Equivalent circuit of the IG connection to the distribution network

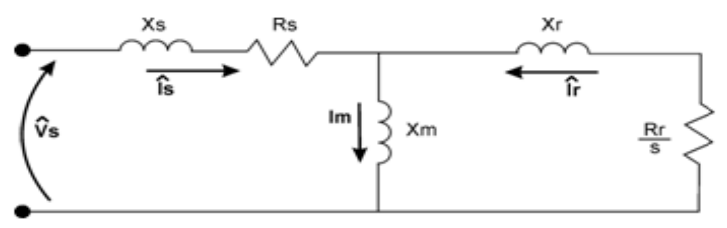

Fig. 2: One-phase equivalent circuit of the IG

Classic model: The IG can be analyzed according to its classical model, illustrated in Fig. 2, that represents the one-phase equivalent circuit of the machine (Kundur, 1994; Barbi, 2008).

In this figure, stability assessment $\mathrm{Vs}$ is the terminal stator voltage, $\mathrm{X}_{\mathrm{s}}$ is the stator reactance, $\mathrm{R}_{\mathrm{s}}$ is the stator resistance, Is corresponds to the stator current, $\mathrm{X}_{\mathrm{m}}$ is the magnetizing reactance, Im corresponds to the magnetizing current, $\mathrm{Xr}$ is the rotor reactance, $\mathrm{R}_{\mathrm{r}}$ is the rotor resistance, " $\mathrm{S}$ " is the rotor slip and Iy is the rotor current. These variables are all expressed in per unit quantities and referred to the stator side of the machine: Determination of Iy.

It is worth mentioning that the magnitude of the rotor current is of great importance when describing the equations related to the electrical-mechanical equilibrium condition, as will be seen in the next Subsection. Thus, in order to determine Iy, the equivalent circuit depicted in Fig. 2 can be mathematically described by:

$$
\left[\begin{array}{c}
\hat{V}_{s} \\
\hat{0}
\end{array}\right]=\left[\begin{array}{cc}
\mathrm{R}_{\mathrm{s}}+\mathrm{j}\left(\mathrm{X}_{\mathrm{s}}+\mathrm{X}_{\mathrm{m}}\right) & \mathrm{j} \mathrm{X}_{\mathrm{m}} \\
\mathrm{j} \mathrm{X}_{\mathrm{m}} & \frac{\mathrm{R}_{\mathrm{r}}}{\mathrm{s}}+\mathrm{j}\left(\mathrm{X}_{\mathrm{r}}+\mathrm{X}_{\mathrm{m}}\right)
\end{array}\right] \cdot\left[\begin{array}{c}
\hat{\mathrm{I}}_{\mathrm{s}} \\
\hat{\mathrm{I}}_{\mathrm{r}}
\end{array}\right]
$$

Solving the set of Eq. (1), one can determine $\hat{\mathrm{I}}_{r}$ as described by:

$$
\hat{\mathrm{I}}_{\mathrm{r}}=\frac{\left[-j X_{m}\right]}{\frac{\mathrm{R}_{\mathrm{s}} \cdot \mathrm{R}_{\mathrm{r}}}{\mathrm{s}}+\mathrm{K}_{1}+\mathrm{j} \cdot\left[\mathrm{R}_{\mathrm{s}} \mathrm{K}_{2}+\frac{\mathrm{R}_{\mathrm{r}}}{\mathrm{s}} \cdot \mathrm{K}_{3}\right]} \cdot \hat{\mathrm{V}}_{\mathrm{s}}
$$

In this equation, $K_{1}, K_{2}$ and $K_{3}$ are constants defined using the electrical parameters of the IG and can be written as follows: 


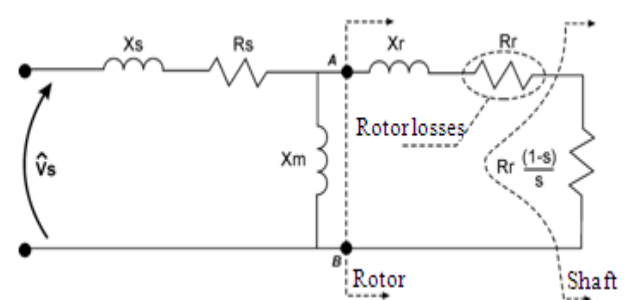

Fig. 3: Alternative form of the one-phase IG equivalent circuit

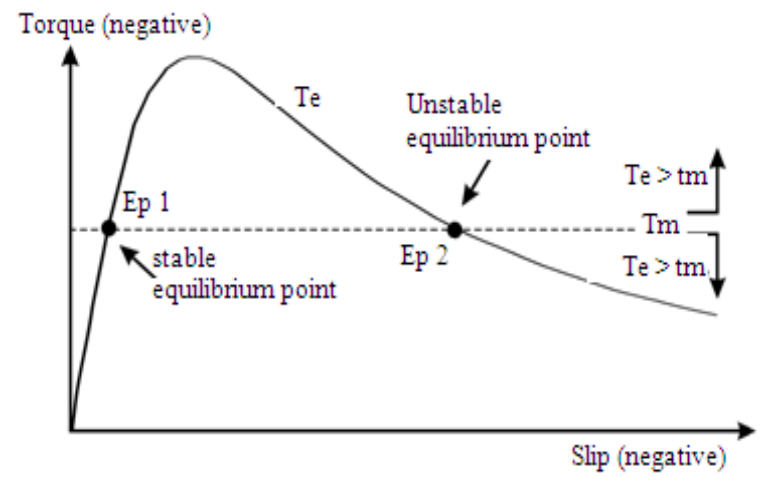

Fig. 4: Electrical and mechanical torque curves

$$
\begin{aligned}
& \mathrm{K}_{1}=\mathrm{X}_{\mathrm{m}}{ }^{2}-\left(\mathrm{X}_{\mathrm{s}}+\mathrm{X}_{\mathrm{m}}\right) \cdot\left(\mathrm{X}_{\mathrm{r}}+\mathrm{X}_{\mathrm{m}}\right) \\
& \mathrm{K}_{2}=\mathrm{X}_{\mathrm{r}}+\mathrm{X}_{\mathrm{m}} \\
& \mathrm{K}_{3}=\mathrm{X}_{\mathrm{s}}+\mathrm{X}_{\mathrm{m}}
\end{aligned}
$$

So, the magnitude of Iy is:

$$
\left|\hat{I}_{r}\right|=I_{r}=\frac{\left[X_{m}\right]}{\sqrt{\left(\frac{R_{r}}{s} \cdot R_{s}+K_{1}\right)^{2}+\left(R_{s} \cdot K_{2}+\frac{R_{r}}{s} \cdot K_{3}\right)^{2}}} \cdot V_{s}
$$

where, $\mathrm{V}_{\mathrm{s}}$ is the magnitude of the voltage phasor $\mathrm{V}_{\mathrm{s}}$.

Electrical-mechanical Equilibrium Equations. is:

The mechanical power (Pm) transferred to the shaft

$\mathrm{P}_{\mathrm{m}}=\omega_{\text {shaft }} \cdot \mathrm{T}_{\mathrm{m}}=(1-\mathrm{s}) \cdot \mathrm{T}_{\mathrm{m}}$

Where:

$$
\begin{aligned}
& \omega_{\text {shaft }}=\text { Shaft speed } \\
& \mathrm{T}_{\mathrm{m}}=\text { Mechanical torque }
\end{aligned}
$$

The power received by the rotor $(\mathrm{Pe})$ is equal to the power associated to the rotor resistance, referred to the stator side and discounting the rotor power losses, as described in (6):

$$
P_{e}=\frac{R_{r}}{s} \cdot\left|\hat{I}_{r}\right|^{2}-R_{r} \cdot\left|\hat{I}_{r}\right|^{2}=(1-s) \cdot \frac{R_{r}}{s} \cdot\left|\hat{I}_{r}\right|^{2}
$$

This equation leads to the well-known alternative form of the IG one-phase equivalent circuit, as shown in Fig. 3.

At electrical-mechanical equilibrium conditions, the net power associated to the shaft is zero. This means that all power provided by the primary source is equal to the power generated in the rotor and required to attend the electrical load, as in (7).

$\mathrm{P}_{\mathrm{m}}=\mathrm{P}_{\mathrm{e}}$

From (5-7), one can write:

$\mathrm{T}_{\mathrm{m}}=\frac{\mathrm{R}_{\mathrm{r}}}{\mathrm{s}} \cdot\left|\hat{\mathrm{I}}_{\mathrm{r}}\right|^{2}$

Substituting (4) in (8) and considering electricalmechanical equilibrium conditions, the electrical torque Te associated to the shaft can be defined as in Eq. 9:

$\mathrm{T}_{\mathrm{m}}=\mathrm{T}_{\mathrm{e}}=\frac{\frac{\mathrm{R}_{\mathrm{r}}}{\mathrm{s}} \cdot \mathrm{X}_{\mathrm{m}}{ }^{2}}{\left(\frac{\mathrm{R}_{\mathrm{r}}}{\mathrm{s}} \cdot \mathrm{R}_{\mathrm{s}}+\mathrm{K}_{1}\right)^{2}+\left(\mathrm{R}_{\mathrm{s}} \cdot \mathrm{K}_{2}+\frac{\mathrm{R}_{\mathrm{r}}}{\mathrm{s}} \cdot \mathrm{K}_{3}\right)^{2}} \cdot \mathrm{V}_{\mathrm{s}}^{2}$

Defining the constant $\mathrm{K}_{4}$ as:

$\mathrm{K}_{4}=\frac{\mathrm{T}_{\mathrm{m}}}{\mathrm{V}_{\mathrm{s}}^{2}}$

One can rewrite (9) as:

$\frac{\mathrm{s} \cdot\left(\mathrm{R}_{\mathrm{r}} \cdot \mathrm{X}_{\mathrm{m}}{ }^{2}\right)}{\mathrm{s}^{2} \cdot\left(\mathrm{K}_{1}{ }^{2}+\mathrm{R}_{\mathrm{s}}{ }^{2} \cdot \mathrm{K}_{2}{ }^{2}\right)+\mathrm{s} \cdot\left(2 \cdot \mathrm{R}_{\mathrm{r}} \cdot \mathrm{R}_{\mathrm{s}} \cdot \mathrm{X}_{\mathrm{m}}{ }^{2}\right)}=\mathrm{K}_{4}$

$+\mathrm{R}_{\mathrm{r}}{ }^{2} \cdot\left(\mathrm{K}_{3}{ }^{2}+\mathrm{R}_{\mathrm{s}}{ }^{2}\right)$

Or:

$$
\begin{aligned}
& \mathrm{s}^{2} \cdot\left(\mathrm{K}_{1}{ }^{2}+\mathrm{R}_{\mathrm{s}}{ }^{2} \cdot \mathrm{K}_{2}{ }^{2}\right)+ \\
& +\mathrm{s} .\left(2 \cdot \mathrm{R}_{\mathrm{r}} \cdot \mathrm{R}_{\mathrm{s}} \cdot \mathrm{X}_{\mathrm{m}}{ }^{2}-\frac{\left(\mathrm{R}_{\mathrm{r}} \mathrm{X}_{\mathrm{m}}{ }^{2}\right)}{\mathrm{K}_{4}}\right)+ \\
& +\mathrm{R}_{\mathrm{r}}{ }^{2} \cdot\left(\mathrm{K}_{3}{ }^{2}+\mathrm{R}_{\mathrm{s}}{ }^{2}\right)=0
\end{aligned}
$$


As expected, this last equation shows that the solution of the electrical-mechanical equilibrium equation is a function of the slip s. If the IG parameters and the voltage magnitude $\mathrm{V}_{\mathrm{S}}$ are known, Eq. 12 can be used to determine slip values corresponding to two possible equilibrium points. Figure 4 illustrates the curves of the electrical torque Te and the mechanical torque Tm as functions of the IG slip (or speed). In this Figure it is assumed that the terminal voltage $V_{S}$ after the fault elimination is equal to the one before the fault occurrence (characterizing a condition where the generator is connected to an infinite bus). As mentioned, two electrical-mechanical equilibrium points related to the IG operation can be determined, considering a constant mechanical torque. In Fig. 4, they correspond to the crossings of the mechanical and electrical torque curves, marked as point EP1 (stable) and point EP2 (unstable).

Solving (9), one can determine the slips ( $s_{1}$ and $s_{2}$ ) associated to these equilibrium points. They correspond to the roots of (12) and can be calculated by (13):

$\mathrm{s}_{1}=\frac{-\mathrm{b}+\sqrt{\Delta}}{2 \cdot \mathrm{a}}$ and $\mathrm{s}_{2}=\frac{-\mathrm{b}-\sqrt{\Delta}}{2 \cdot \mathrm{a}}$

Where:

$\mathrm{a}=\mathrm{K}_{1}^{2}+\mathrm{R}_{\mathrm{s}}{ }^{2} \cdot \mathrm{K}_{2}^{2} ;\left(\mathrm{R}_{\mathrm{r}} \cdot \mathrm{X}_{\mathrm{m}}{ }^{2}\right)$
$\mathrm{b}=2 \cdot \mathrm{R}_{\mathrm{r}} \cdot \mathrm{R}_{\mathrm{s}} \cdot \mathrm{X}_{\mathrm{m}}{ }^{2}-\frac{\mathrm{K}_{4}}{\mathrm{c}} ; \mathrm{R}_{\mathrm{r}} \cdot\left(\mathrm{K}_{3}{ }^{2}+\mathrm{R}_{\mathrm{s}}\right) \cdot \mathrm{K}_{4}$

And:

$\Delta=\mathrm{b}^{2}-4$. a.c

By performing a signal analysis, one can verify that the absolute value of root $s_{2}$ is larger than $s_{1}$. Consequently, $s_{1}$ characterizes the steady-state stable operation point and $s_{2}$ is the slip value related to the unstable operation point EP2, as shown in Fig. 5.

So, the critical speed is the shaft speed related to the point EP2 and to the slip $s_{2}$. It can be obtained using (16):

$\omega_{\text {crit }}=\omega_{\text {sync }} \cdot\left(1-\mathrm{s}_{2}\right)=1-\frac{-\mathrm{b}-\sqrt{\Delta}}{2 \cdot \mathrm{a}}$

Where:

$\omega_{\text {sync }}=$ Synchronous speed
Fault-condition analysis and critical time determination: Assuming that the shaft speed $\left(\omega_{\text {shaft }}\right)$ in the moment of the fault $\left(\mathrm{t}_{\mathrm{f}}\right)$ is the shaft speed associated to the stable steady-state point $\left(\omega_{0}\right)$, one can write:

$\omega_{\text {shaft }}\left(t_{\mathrm{f}}\right)=\omega_{0}=\omega_{\text {sync }} \cdot\left(1-\mathrm{s}_{1}\right)=1-\frac{-\mathrm{b}+\sqrt{\Delta}}{2 \cdot \mathrm{a}}$

During a fault, the balance between the electrical and the mechanical power is compromised. The fault is assumed here as a three-phase short circuit and, consequently, the steady-state terminal voltage $V_{S}$ during the fault is null. In this case, the electrical output power can also be considered null. So, based on Eq. (9), $T_{e}=0$ and the shaft accelerates due to the mechanical torque Tm only. The shaft angular acceleration in this condition can be expressed by:

$\alpha(\omega)=\frac{T_{\text {net }}}{J(\omega)}=\frac{T_{e}-T_{m}}{J(\omega)}=\frac{-T_{m}}{J(\omega)}$

where, $J(\omega)$ is the generator inertial moment, that is dependant on the shaft speed (and, consequently, on the slip). Considering that the fault is cleared at the instant $t_{c}$, the shaft speed $\omega_{\text {shaft }}$ will be ruled by the following equation:

$\omega_{\text {shaft }}=\omega_{0}+\int_{\text {tf }}^{\text {tc }} \alpha \cdot \partial t$

Also considering that the inertial moment is constant along the process and is equal to the one encountered at the synchronous speed $\omega_{\text {sync }}\left(\omega_{\text {sync }}=1\right.$ p.u.), it can be defined as a function of the IG synchronous inertial constant $\mathrm{H}$, i.e., $\mathrm{J}\left(\omega_{\text {sync }}\right)=2 . \mathrm{H}$. Thus, (18) can be rewritten as:

$\alpha_{\text {sync }}=\frac{T_{\text {net }}}{J\left(\omega_{\text {sync }}\right)}=\frac{T_{\text {net }}}{2 . H}=-\frac{T_{m}}{2 . H}$

where, $\alpha_{\text {ynce }}$ is the shaft constant angular acceleration based on $\mathrm{J}\left(\omega_{\text {sync }}\right)$. From (19), the shaft speed becomes:

$\omega_{\text {shaft }}=\omega_{\mathrm{o}}+\alpha_{\text {sync }} \cdot\left(\mathrm{t}_{\mathrm{c}}-\mathrm{t}_{\mathrm{f}}\right)$ 


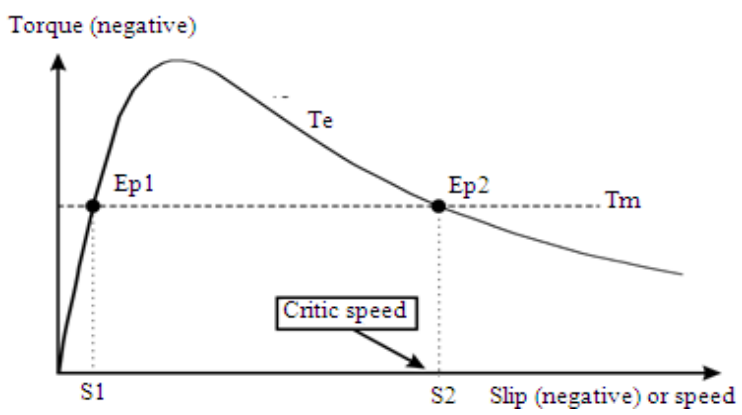

Fig. 5: Equilibrium points and critical speed

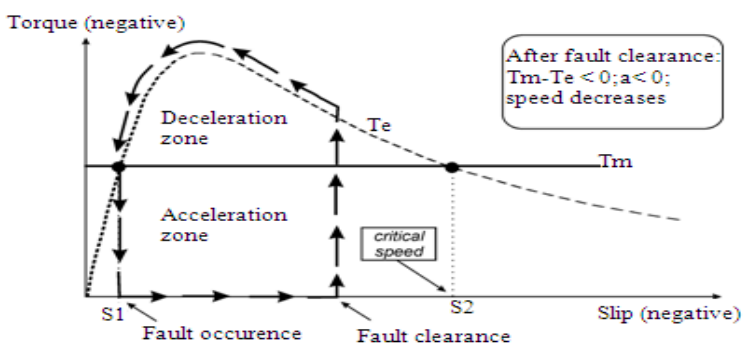

Fig. 6: IG torque-slip behavior for clearance shaft speed lesser than the critical speed $\left(\omega_{\text {shaft }}<\omega_{\text {crit }}\right)$

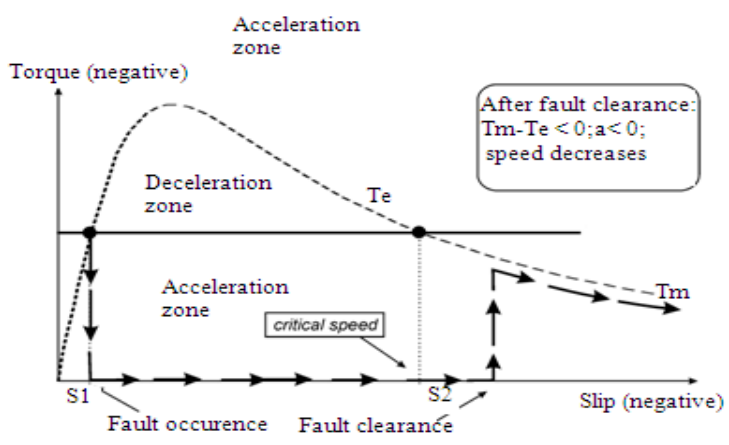

Fig. 7: IG torque-slip behavior for clearance shaft speed greater than the critical speed $\left(\omega_{\text {shaft }}>\omega_{\text {crit }}\right)$

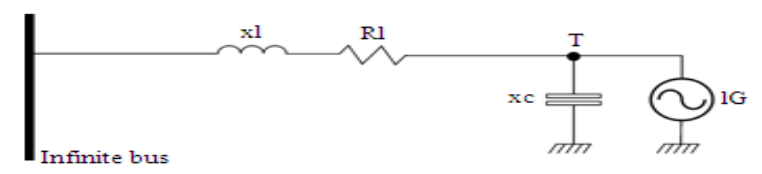

Fig. 8: Electric network equivalent circuit

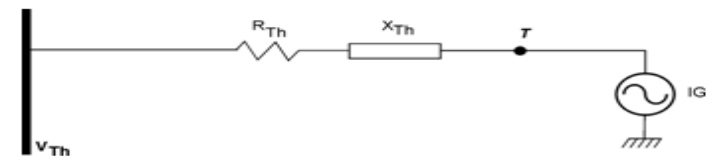

Fig. 9: Reduced electric network equivalent circuit
If the shaft speed at the instant of the fault clearance is smaller than the critical speed $\left(\omega_{\text {shaft }}<\right.$ $\omega_{\text {crit }}$, the generator, when reconnected, will present an electrical torque higher than the mechanical torque, as shown in Fig. 6. At the instant of the fault clearance, the net torque imposed to the shaft, $T_{\text {net }}=T_{e}-T_{e}$, will be negative. Thus, the acceleration associated to the shaft will also be negative and the shaft speed will decrease until the steady-state operation speed $\omega_{0}$. So, in this case, the generator will present a stable behavior.

On the other hand, if the shaft speed at the instant of fault clearance is greater than the critical speed $\left(\omega_{\text {shaft }}\right.$ $\left.>\omega_{\text {crit }}\right)$, the generator, when reconnected, will have an electrical torque smaller than the mechanical torque. Consequently, the acceleration associated to the shaft will be positive and the speed will increase further, leading to disconnection by protection tripping. Figure 7 illustrates this situation.

From these results, the IG critical time can be defined as the time required by the shaft to accelerate from $\omega_{0}=\mathrm{f}\left(\mathrm{s}_{1}\right)$ to $\omega_{\text {crit }}=\mathrm{f}\left(\mathrm{s}_{2}\right)$ during a fault condition. If the fault lasts for a time higher than the critical time, the generator accelerates further than the critical speed and loses its stability. So, this critical time ( $\left.\mathrm{t}_{\text {crit }}\right)$ determines the maximum allowable clearance fault time that guarantees stable operational conditions.

This value can be obtained by the time difference between the fault occurrence and its clearance for the most critical situation: when the generator shaft speed is equal to the critical speed in the reconnection instant. In this case, Eq. 21 can be rewritten as:

$$
\omega_{\text {shaft }}=\omega_{\text {crit }}=\omega_{0}+\alpha \cdot\left(t_{\text {crit }}\right)
$$

Assuming null electrical torque during the fault (3phase fault), this expression becomes:

$$
\mathrm{t}_{\text {crit }}=\frac{\omega_{\text {crit }}-\omega_{0}}{\alpha}=-\frac{2 \cdot H \cdot\left(\omega_{\text {crit }}-\omega_{0}\right)}{T_{m}}
$$

Line parameters consideration: In the previous equations, the terminal voltage $V_{S}$ was assumed as known and constant, conserving the same value before the fault occurrence and after its elimination. However, in actual networks, the voltage drop across the line cannot be ignored. This electrical variable has a significant impact on the critical time determination. So, in order to consider a more generic fault situation, a different IG equivalent circuit must be adopted. Initially, lets consider that the electric distribution network, previously presented in Fig. 1, can be reduced to its equivalent circuit, as shown in Fig. 8. 


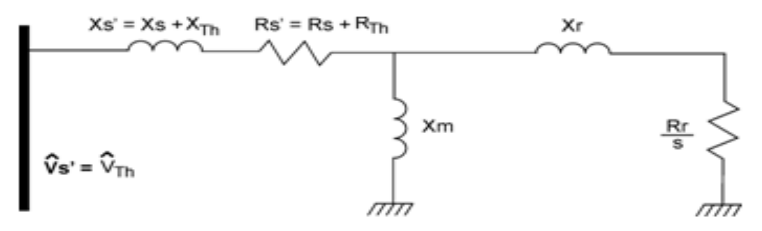

Fig. 10: Equivalent generator circuit-line parameters plus induction machine

In this circuit, the line reactance and resistance are aggregated with the reactance and resistance of the transformer, resulting in the equivalent parameters XL and $\mathrm{RL}$. The point $\mathrm{T}$ corresponds to the machine terminals and $X C$ is the reactance of the capacitor bank. Considering prefault conditions, the network can be reduced (using the Thevenin's equivalent) as shown in Fig. 9.

In this case, the equivalent parameters are expressed by:

$$
\begin{aligned}
& R_{T h}=\frac{R_{L} \cdot X_{C}{ }^{2}}{R_{L}{ }^{2}+\left(X_{L}-X_{C}\right)^{2}} \\
& X_{T h}=\frac{-R_{L}^{2} \cdot X_{C}-X_{L} \cdot X_{C} \cdot\left(X_{L}-X_{C}\right)}{R_{L}^{2}+\left(X_{L}-X_{C}\right)^{2}} \\
& \hat{V}_{T h}=\frac{-j \cdot X_{C}}{R_{L}+j \cdot\left(X_{L}-X_{C}\right)} \cdot \hat{V}_{I B}
\end{aligned}
$$

where, $\mathrm{V}_{\mathrm{IB}}$ is voltage phasor at the infinite bus.

Thus:

$$
\left|\hat{\mathrm{V}}_{\mathrm{Th}}\right|=\frac{\mathrm{X}_{\mathrm{C}}}{\sqrt{\mathrm{R}_{\mathrm{L}}{ }^{2}+\left(\mathrm{X}_{\mathrm{L}}-\mathrm{X}_{\mathrm{C}}\right)^{2}}} \cdot\left|\hat{\mathrm{V}}_{\mathrm{IB}}\right|
$$

Now, it is possible to define:

$$
\begin{aligned}
& \mathrm{R}_{\mathrm{s}}^{\prime}=\mathrm{R}_{\mathrm{Th}}+\mathrm{R}_{\mathrm{s}} \\
& \mathrm{X}_{\mathrm{s}}^{\prime}=\mathrm{X}_{\mathrm{Th}}+\mathrm{X}_{\mathrm{s}} \\
& \mathrm{V}_{\mathrm{s}}^{\prime}=\mathrm{V}_{\mathrm{Th}}
\end{aligned}
$$

Furthermore, using these equivalent parameters, the line and the induction machine can be aggregated in a circuit that corresponds to an equivalent generator, as shown in Fig. 10. This equivalent generator can be used to solve the electrical-mechanical equilibrium equations and to assess the critical time for different values of line parameters, using the same equations defined before.

It is important to note that any transient electrical power output that can arise during the fault, due to the energy stored in the machine electromagnetic fields or in the capacitor, will imply in a non-null terminal voltage $V_{S}$ and in an electrical torque $T_{e}$ different from zero during a short period of time after the beginning of the fault. Consequently, the shaft will be subjected to an accelerating torque smaller than $\mathrm{T}_{\mathrm{m}}$ during the initial instants of the fault.

Hence, the hypothesis that $\mathrm{T}_{\mathrm{e}}=0$ during the fault, assumed in the development of Eq. 18-23, corresponds to the most critical case that can occur in a fault situation in terms of stability. So, the results obtained from the analytical approach are expected to be conservative and, during the fault, it can be considered that $V_{S}$ is zero without deterioration of the reliability of the method.

Analytical method for stability assessment: The stability assessment of IGs can then be reduced to the following problem: the determination of the critical time, given the generator parameters, the mechanical torque at the shaft, the line parameters and the fault occurrence instant. Considering this, the methodology proposed in this work can be summarized by the following procedure:

Step 1: Determine the parameters of the equivalent induction generator ( $\mathrm{R} \mathrm{X}$ and V) using Eq. 24 through (30).

Step 2: Determine the constants $\mathrm{K}_{1}, \mathrm{~K}_{2}, \mathrm{~K}_{3}$ and $\mathrm{K} 4$. This can be done using (3) and (10). Then, determine the parameters a, b and $c$, as described in (14).

Step 3: Verify if the problem data correspond to a stable condition using Eq. 15. In this case, during the determination of $\Delta$, one of the following situations can occur:

- $\Delta>0$ : Eq. (12) possesses two real roots and, consequently, one stable solution. Thus, the critical time can be determined

- $\Delta=0$ : Eq. (12) possesses one real root, e.g., an unstable solution and the critical time is null

- $\Delta<0$ : Eq. (12) does not possess a real root. There is no possible equilibrium between the electrical and the mechanical torques and so the concept of critical time cannot be applied

Step 4: If there is a stable solution, e.g., $\Delta \leq 0$, determine the slips $s_{1}$ and $s_{2}$ and the speeds $\omega_{0}$ and $\omega_{\text {crit }}$, using (13), (16) and (17). Then, determine the critical time, using (23).

\section{RESULTS}

Test system: In order to validate the proposed method, the developed formulation is compared with computational simulations, using the 
SymPowerSystems package for MATLAB/SIMULINK (TransEnergie Technologies Inc., 2004). Figure 11 illustrates the one-line diagram of the adopted test system. This system consists of a $132 \mathrm{kV}, 60 \mathrm{~Hz}$ subtransmission system that feeds a $33-\mathrm{kV}$ distribution network through a $132 / 33-\mathrm{KV} \Delta$-Y transformer. The generator is a 10 MVA, $2400 \mathrm{~V}$ induction machine connected to the network through a 33/2,4-KV Y- $\Delta$ transformer. The distribution line has a length of 10 miles.

The equivalent circuit parameters and power injections associated to Fig. 8 are shown in Table 1. The parameters adopted to represent the generator, using its classical one-phase model, previously shown in Fig. 2, are described in Table 2. All of these parameters are referred to the induction machine base values (2400 V and $10 \mathrm{MVA}$ ).

As can be seen in Table 1, the loads associated to buses 2 and 3 were nullified. This hypothesis was adopted in order to guarantee the worse stability condition. If the system has no loads, there is no possibility of power drain to attend them during and after the fault, i.e., none contribution for electrical output power at the machine terminals is made by the loads. Any transient electrical torque at the rotor is, then, minimized during the fault.

Critical speed determination: The objective of the first test was to verify the behavior of the IG rotor speed determined by the developed equations and the simulations. The simulations yielded a set of curves, as shown in Fig. 12. The first curve was obtained for a fault elimination time $t_{e}$ equals to $410 \mathrm{~ms}$. In the subsequent curves, the fault time was progressively incremented by $5 \mathrm{~ms}$. As expected, the generator behavior changes from stable to unstable as the fault time increases. The edge of stability occurs for a fault elimination time $\mathrm{t}_{\mathrm{e}}$ between 435 and $440 \mathrm{~ms}$.

The analytical critical speed in this case, obtained through Eq. 23, is equal to 1,154 p.u. This value can be compared with the simulations, as shown in Fig. 13, by "zooming” the fault elimination region of Fig. 12. The dashed line in Fig. 13 represents the analytical critical speed.

In Fig. 13, the paths followed by the unstable curves are all located above the analytical speed line, while the ones followed by the stable curves are located below it. This means that none simulated curve disagrees with the analytical result.

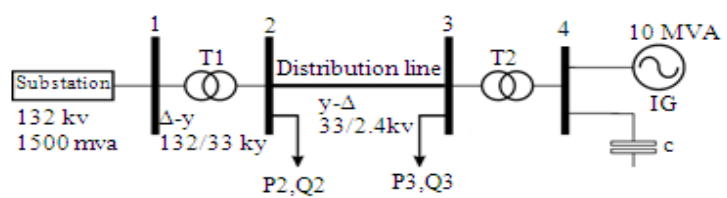

Fig. 11: One-line diagram of the test system

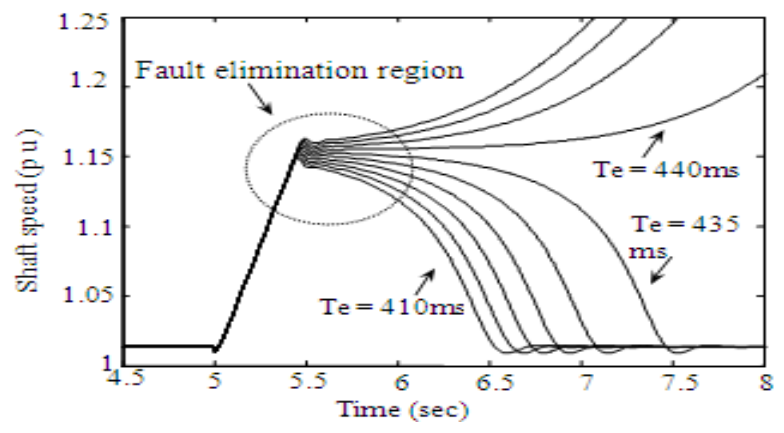

Fig. 12: Shaft speed behavior for different fault times

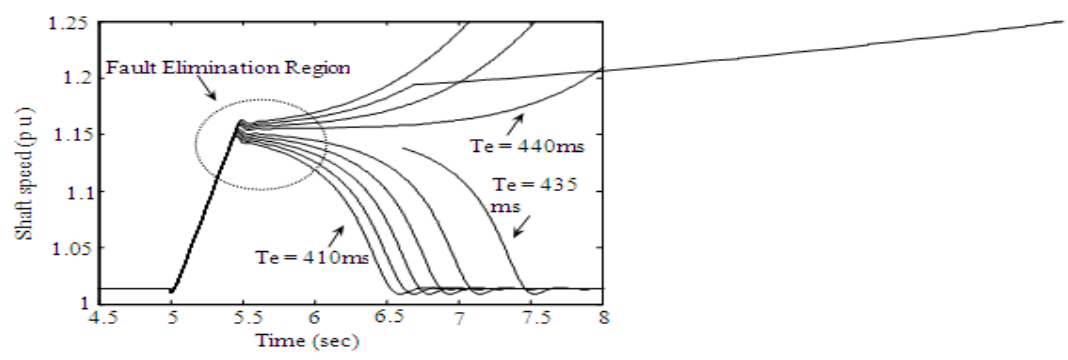

Fig. 13: Comparison between analytical critical speed and simulations 
Table 1: Equivalent line parameters and bus power injections

\begin{tabular}{llll}
\hline Parameter & Value (p.u) & Parameter & Value (p.u) \\
\hline RL & 0.1 & XL & 0.10 \\
P2 & 0.0 & Q2 & 0.00 \\
P3 & 0.0 & Q3 & 0.00 \\
VIB & 1.0 & QC & 0.20 \\
\hline
\end{tabular}

Table 2: Equivalent parameters of the induction generator

\begin{tabular}{lc}
\hline Parameter & Value (p.u) \\
\hline $\mathrm{X}_{\mathrm{s}}$ & 0.100 \\
$\mathrm{R}_{\mathrm{s}}$ & 0.010 \\
$\mathrm{X}_{\mathrm{r}}$ & 0.098 \\
$\mathrm{R}_{\mathrm{r}}$ & 0.014 \\
$\mathrm{X}_{\mathrm{m}}$ & 3.500 \\
$\mathrm{H}$ & 1.500 \\
$\mathrm{~T}_{\mathrm{m}}$ & -1.000 \\
\hline
\end{tabular}

Table 3: Results for ig parameters variation

\begin{tabular}{llll}
\hline & Analytical & Simulated & \\
Parameter (p.u.) & value (ms) & value (ms) & Error (\%) \\
\hline $\mathrm{R}_{\mathrm{r}}=0.0105$ & 317 & 332 & 4.5 \\
$\mathrm{R}_{\mathrm{r}}=0.0140$ & 423 & 437 & 3.2 \\
$\mathrm{R}_{\mathrm{r}}=0.0210$ & 634 & 659 & 3.8 \\
$\mathrm{X}_{\mathrm{r}}=0.0490$ & 616 & 646 & 4.6 \\
$\mathrm{X}_{\mathrm{r}}=0.1470$ & 296 & 301 & 1.7 \\
$\mathrm{X}_{\mathrm{r}}=0.2940$ & 93 & 103 & 9.7 \\
$\mathrm{R}_{\mathrm{s}}=0.0050$ & 424 & 444 & 4.5 \\
$\mathrm{R}_{\mathrm{s}}=0.0150$ & 422 & 437 & 3.4 \\
$\mathrm{R}_{\mathrm{s}}=0.0200$ & 420 & 440 & 4.5 \\
$\mathrm{X}_{\mathrm{s}}=0.0500$ & 613 & 643 & 4.2 \\
$\mathrm{X}_{\mathrm{s}}=0.1500$ & 296 & 301 & 1.7 \\
$\mathrm{X}_{\mathrm{s}}=0.3000$ & 77 & 82 & 6.1 \\
$\mathrm{X}_{\mathrm{m}}=1.7500$ & 393 & 403 & 2.5 \\
$\mathrm{X}_{\mathrm{m}}=5.2500$ & 433 & 453 & 4.4 \\
$\mathrm{X}_{\mathrm{m}}=7.0000$ & 438 & 458 & 4.4 \\
\hline
\end{tabular}

Table 4: Results for capacitor bank variation

\begin{tabular}{llll}
\hline $\begin{array}{l}\text { Capacitor bank } \\
\text { (MVAr) }\end{array}$ & $\begin{array}{l}\text { Analytical } \\
\text { value (ms) }\end{array}$ & $\begin{array}{l}\text { Simulated } \\
\text { value (ms) }\end{array}$ & Error (\%) \\
\hline 0.0 & 404 & 418 & 3.3 \\
0.7 & 411 & 425 & 3.3 \\
1.3 & 417 & 431 & 3.2 \\
2.0 & 423 & 438 & 3.4 \\
4.0 & 442 & 462 & 4.3 \\
\hline
\end{tabular}

Variation of generator parameters: The objective of this test was to compare analytical and simulated critical times, for different values of generator parameters, previously described in Table 2. These results, shown in Table 2, were obtained changing only one specified parameter at a time, while the others remain constant. In each case, the analytical critical time was obtained by applying the proposed method, while sequential dynamic simulations yielded the simulated critical time.

The results obtained by the analytical approach are all conservative and a good match (all errors are less than $10 \%$ ) can be observed between them and the results obtained by simulation.
Impacts of capacitor bank variation: $A s$ in the previous case, the objective of this test was to make a comparison between the analytical and the simulated critical times, but now for different values of the capacitor bank. For this test, QC was considered ranging from 0 through 4 MVAr. Table 4 illustrates the comparison between the analytical and the simulated critical times in this case.

These data indicate that the capacitor bank has a positive influence on the critical time, for greater values of QC results on greater critical times. This can be observed both in the analytical and the simulated results.

\section{DISCUSSION}

Table 3 presents the percentual mean absolute error calculated between the analytical results and the simulated ones.

The low mean errors (less than 5\%) obtained in all cases attest the reliability of the analytical calculations. It must be emphasized that all these error margins are conservative, i.e., the analytical critical times are always smaller than the simulated ones. This fact naturally suggests that the analytical approach can be successfully used to determine an initial solution for the dynamic simulations.

\section{CONCLUSION}

This work proposed a simple analytical method for assessing the speed stability of induction generators connected to distribution systems. This method is based on equations related to the electrical-mechanical equilibrium found at normal operation conditions, that is violated when the generator is under a fault situation. The simplicity of the steps that compose the assessment method permits its implementation in computational devices with less complexity, as microcontrollers.

Also, the proposed analytical approach promotes the physical understanding of the IG speed stability phenomenon, showing that the calculation of the critical time is a simple and useful method to assess the speed stability of induction generators. Furthermore, the comparison between the analytical and simulation results shows that the developed methodology can adequately determine the critical speed and critical time of the IG and, consequently, reliable assess its speed stability when subjected to disturbances. Finally, the validation results demonstrate that the proposed method is sufficiently accurate and can be used as a start point to reduce the number of simulations required when the speed stability of IGs installed in distribution networks must be determined. 


\section{REFERENCES}

Akhmatov, V. 2003. Analysis of dynamic behavior of electric power systems with large amount of wind power, $\mathrm{PhD}$ Thesis. Technical University of Denmark.

http://www.studenterpraest.dtu.dk/upload/centre/ce t/projekter/05-va-thesis.pdf

Akhmatov, V., H. Knudsen, A.H. Nielsen, J.K. Pedersen and N.K. Poulsen et al., 2003. Modeling and transient stability of large wind farms. Int. J. Elect. Power Energy Syst., 25: 1123-144. DOI: 10.1016/S0142-0615(02)00017-0

Barbi, I., 2008. Fundamental Theory of Induction Motors. INEP-UFSC-Brazilian Power Electronic Institute, Florianopolis, pp: 242. http://www.ivobarbi.com

Jenkins, N., R. Allan, P. Crossley, D. Kirschen and G. Strbac, 2000. Embedded Generation. 1st Ed., The Institution of Electrical Engineers, London, ISBN: 978-0-85296-774-4, pp: 292.

Kundur, P., 1994. Power System Stability and Control. 1st Ed., McGraw-Hill, New York, ISBN: 007035958X, pp: 1176.
Lubis, Z., A.N. Abdalla, Mortaza and R. Ghon, 2009. Mathematical modeling of the three phase induction motor couple to DC motor in hybrid electric vehicle. Am. J. Eng. Applied Sci., 2: 708712. DOI: 10.3844/ajeassp.2009.708.712

Mota, L.T.M. and Mota, A.A., 2009. Wind energy generators sitting and sizing based on uncertain generation pricing. Int. J. Global Energy Issues, 32: 260-277. DOI: 10.1504/IJGEI.2009.030655

Parsons, J.R., 1984. Cogeneration application of induction generators. IEEE Trans. Industry Appli., 20: 497-503. DOI: 10.1109/TIA.1984.4504443

Samuelsson, O. and S. Lindahl, 2005. On speed stability. IEEE Trans. Power Systems, 20: 11791180. DOI: 10.1109/TPWRS.2005.846194

Santos, S.P.Y., E. Delbone, E.F. Carvalho and L.N. Martins, 2010. Synchronous generator disturbance provoked by induction motor starting. Am. J. Applied Sci., 7: 962-968. DOI: 10.3844/ajassp.2010.962.968

Willis, H.L. and W.G. Scott, 2000. Distributed Power Generation-Planning and Evaluation. 1st Ed., Marcel Dekker, New York, ISBN: 9780824703363, pp: 616. 